\title{
Reflexões acerca da estrutura curricular para a educação infantil ${ }^{1}$
}

\author{
Myrtes Dias da Cunha ${ }^{2}$ \\ Cecilia Rezende Silva ${ }^{3}$
}

\begin{abstract}
RESUMO
Este artigo buscar refletir sobre a função da escola, em especial, da Educação Infantil. Como seus currículos podem favorecer ou dificultar uma formação integral enquanto cidadãos críticos e ativos numa sociedade cada vez mais consumista. Sabemos que o currículo possui um caráter político e histórico, indo muito além de um simples processo de transmissão de conteúdo. Assim, refletimos sobre o papel docente enquanto agente de reprodução ou emancipação. A partir de uma breve análise da Base Nacional Curricular Comum e outros documentos legais questionamos como as culturas podem ser valorizadas e trabalhadas no contexto escolar, de que forma pode-se favorecer a construção das identidades. Uma reflexão importante deve ser feita em relação ao direito de ser criança, em contrapartida ao processo de escolarização precoce.
\end{abstract}

PALAVRAS-CHAVE: Currículo; Infância; Escolarização precoce; Emancipação.

\section{Reflections on the curricular structure for child education}

\begin{abstract}
This article seeks to reflect on the role of the school, especially in Early Childhood Education. How their curricula can favor or hinder an integral formation as critical and active citizens in an increasingly consumerist
\end{abstract}

\footnotetext{
${ }^{1} \mathrm{O}$ artigo foi produzido no âmbito do curso de mestrado acadêmico em andamento.

2 Doutora em Educação, professora titular da Faculdade de Educação da Universidade Federal de Uberlândia, Minas Gerais, Brasil. E-mail: myrtesufu@gmail.com

${ }^{3}$ Graduada em Pedagogia. Especialista em Educação Especial. Estudante do Ppged da Universidade Federal de Uberlândia no nível de mestrado. Professora na rede municipal de ensino de Uberlândia/MG. E-mail: ceciliarezende@ufu.br
} 
society. We know that the curriculum has a political and historical character, going far beyond a simple process of content transmission. Thus, we reflect on the teaching role as agent of reproduction or emancipation. From a brief analysis of the National Curricular Base and other legal documents, we questioned how cultures can be valued and worked in the school context, in what way it can favor the construction of identities. An important consideration should be made regarding the right to be a child, in exchange for the process of early literacy.

KEYWORDS: Curriculum; Childhood; Early schooling; Emancipation.

\section{Introdução}

A Educação Infantil (EI), primeira etapa da educação básica, é hoje valorizada por ser um campo riquíssimo de desenvolvimentos diversos. Era e continua sendo reconhecida como o período em que os educandos estão sendo preparados para o ensino fundamental, entretanto, há que se considerar que a antecipação de saberes, próprios das etapas posteriores, pode gerar efeitos negativos pois as crianças precisam vivenciar a infância de maneira livre e saudável.

O cenário que se tem hoje é resultado de grandes mudanças ao longo da história da EI. De acordo com Oliveira (2017), a educação brasileira teve forte influência católica, desde a invasão portuguesa em 1500 cujo objetivo era colonizar os povos nativos, com um sistema baseado na repetição, ou seja, a mera transmissão e memorização dos conteúdos, além da disciplinarização dos corpos que ainda é bastante presente em nossas escolas. A primeira Constituição Federal, de 1824, e a primeira Lei Geral de Educação do país, de 15 de outubro de 1827, não previam o atendimento escolar infantil.

De acordo com Oliveira (2017) "a vinda dos imigrantes, nos anos de 1920 e 1930, trouxe consigo estrangeiros mais politizados da Europa que 
iniciaram movimento de reivindicações, dentre elas, pela educação, inclusive, a infantil" (p. 25). Na sequência, o autor cita:

Kuhlmann Jr. (2000) declara que mesmo que o século XX tenha sido chamado de "século da criança", as políticas educacionais do Brasil só começaram a realmente valorizar a criança pequena, tida como pré-escolar, após a adoção da Declaração dos Direitos da Criança, em 1959 (p. 27).

Entretanto, após anos de luta em prol da valorização da EI, ainda não se tem claro o significado de ser criança nas diferentes culturas, conforme aponta Kramer (2000), que questiona qual o papel social da infância na sociedade moderna. Um de seus principais questionamentos se refere a função social da educação frente à heterogeneidade das populações infantis e das contradições da sociedade. De acordo com a Resolução n 05/ 2009 do Conselho Nacional de Educação (CNE):

Art. $4^{0}$ As propostas pedagógicas da Educação Infantil deverão considerar que a criança, centro do planejamento curricular, é sujeito histórico e de direitos que, nas interações, relações e práticas cotidianas que vivencia, constrói sua identidade pessoal e coletiva, brinca, imagina, fantasia, deseja, aprende, observa, experimenta, narra, questiona e constrói sentidos sobre a natureza e a sociedade, produzindo cultura (BRASIL, 2009, grifo nosso).

Não podemos afirmar que as diversas culturas produzidas nas escolas são valorizadas. Tampouco considerar que a heterogeneidade cultural presente no contexto escolar seja a base para a elaboração dos planejamentos pedagógicos. Após anos de luta para o reconhecimento da EI enquanto modalidade primordial para o desenvolvimento do cidadão, ainda se faz presente um ensino tradicional onde a cultura dominante impede a manifestação do diverso. O que observamos é uma corrida em busca da 
alfabetização, onde as crianças estão sendo apressadas a crescer (CORAZZA, 2015), comumente é o processo de disciplinarização, como um tipo de adestramento para a formação do modelo de aluno ideal. Cada vez mais são exigidas das crianças posturas comportamentais e saberes cognitivos impróprios para a suas idades, sendo o currículo o agente principal de manutenção desta ordem.

Assim, refletir sobre o currículo destinado à infância não é tarefa simples. Sabemos que o campo curricular tem sido investigado sob diversas óticas teóricas e políticas. De acordo com Apple (1995) o currículo não se resume um conjunto neutro de conhecimentos. Existe uma tradição seletiva de um grupo de pessoas, que definem qual é o conhecimento legítimo. Para Veiga-Neto (2002) o currículo é um "artefato", é muito mais que uma ordenação de saberes escolarizados. Assim:

A invenção e a propagação do currículo não devem ser entendidas de forma reduzida, isto é, não devem ser entendidas como resultado de inteligentes operações mentais levadas a cabo por educadores e pedagogos preocupados em organizar, da melhor maneira, a educação escolarizada" (VEIGA-NETO, 2002, p. 168, grifo do autor).

A quê os currículos se propõe? Como bem questiona Sacristan (2003) e Young (2007) qual é a função da escola? É claro que todo o planejamento do trabalho escolar está pautado em seus objetivos formativos, que pouco se voltam para o bem estar social.

As escolas são tratadas como um tipo de agência de entregas, que deve se concentrar em resultados e prestar pouca atenção ao processo ou ao conteúdo do que é entregue. Como resultado, os propósitos da escolaridade são definidos em termos cada vez mais instrumentais, como um meio para outros fins. Com as escolas sendo controladas por metas, tarefas e tabelas comparativas de 
desempenho, não é de se espantar que os alunos fiquem entediados e os professores sintam-se desgastados e apáticos (YOUNG, 2007, p. 1291).

Os currículos determinados pelo governo, que seguem uma ordem de dominação internacional (CHIZZOTTI; PONCE, 2012) visam a formação de mão de obra qualificada para o mercado de trabalho, custe o que custar (MOREIRA; SILVA, 1994). Infâncias são massacradas na corrida pela alfabetização com imposições disciplinadoras, o que chamamos de processo de escolarização precoce. Sabemos que o currículo possui um caráter político e histórico, indo muito além de um simples processo de transmissão de conteúdo. Segundo Silva (1995) o currículo, o conhecimento e a cultura são produzidos no contexto das relações sociais e de poder.

De acordo com Gomes (2007) diversos conhecimentos produzidos pela humanidade ainda são excluídos dos currículos e das formações docentes. $\mathrm{O}$ autor cita:

[...] o conhecimento produzido pela comunidade negra ao longo da luta pela superação do racismo, o conhecimento produzido pelas mulheres no processo de luta pela igualdade de gênero, o conhecimento produzido pela juventude na vivência da sua condição juvenil, entre outros. É urgente incorporar esses conhecimentos que versam sobre a produção histórica das diferenças e das desigualdades para superar tratos escolares românticos sobre a diversidade. Para tal, todos nós precisaremos passar por um processo de reeducação do olhar. O reconhecimento e a realização dessa mudança do olhar sobre o "outro" e sobre nós mesmos a partir das diferenças deve superar o apelo romântico ao diverso e ao diferente e construir políticas e práticas pedagógicas e curriculares nas quais a diversidade é uma dimensão constitutiva do currículo, do planejamento das ações, das relações estabelecidas na escola (GOMES, 2007, p. 25-26). 
Mas como trabalhar estes conhecimentos marginalizados num cenário dominado por documentos oficiais que determinam o que deve ser ensinado? Esta tarefa complexa implica romper paradigmas, revestir-se de um empoderamento que muitas vezes não é acessível a maioria dos docentes, seja por sua condição de trabalho, seja pelas avaliações a que são submetidos (avaliações externas para "medir" o nível de qualidade do trabalho ou avaliação de desempenho profissional do próprio professor), e até mesmo pela sociedade (pais e comunidade escolar cobrando por bons resultados). Apesar das dificuldades, esta prática libertadora não é impossível. "Quem abandona as engrenagens da máquina social, tem a sorte de fazer circular a energia elétrica da emancipação" (RANCIÈRE, 2015, p. 151). Assim, cada educador, dentro de suas possibilidades, tem o compromisso de favorecer a liberdade de expressão, o diálogo, o exercício da empatia, o questionamento das estruturas organizacionais, as pequenas rupturas cotidianas (FOUCAULT, 2000) contribuindo assim para a construção de uma sociedade mais justa e democrática.

Diante do exposto, o presente artigo pretende refletir sobre a estrutura curricular prescrita, em outras palavras, o que está definido nos documentos oficiais, a forma como este tem sido aplicado e suas implicações no campo das infâncias.

\section{Ser criança no século XXI}

De acordo com Corazza (2015) a infância nunca foi verdadeiramente assumida. As práticas sociais e culturais não respeitam os anseios dos pequenos cidadão que, imersos numa gama de atividades diárias, pouco tempo conseguem para simplesmente serem crianças. Existem duas realidades: das classes média e alta, onde os pais sobrecarregam seus filhos com atividades de esportes, língua estrangeira, cursos de informática, reforço escolar, dentre outras; a contrapartida é a classe baixa, onde crianças pobres precisam trabalhar para ajudar no sustento da família. E como a escola se posiciona diante destas distintas realidades? Considerar o 
contexto social, cultural e econômico dos alunos deve ser o ponto de partida. Como afirma Sacristan (1995) raramente os conteúdos curriculares terão para os alunos o mesmo significado. Diante de realidades tão distintas, é mesmo impossível que um único planejamento escolar seja capaz de atender as especificidades de cada um dos educandos.

A falta de "representatividade" cultural do currículo escolar repercute, imediatamente, na desigualdade de oportunidades e na incapacidade da cultura da escola para dotar os alunos de instrumentos que os permitam compreender melhor o mundo e a sociedade que os rodeia (SACRISTÁN, 1995, p. 97, grifo do autor).

Assim, nos acrescenta Arroyo (2007) "os educandos nunca foram esquecidos nas propostas curriculares, a questão é com que olhar foram e são vistos" (p. 21). Então nos questionamos: de que forma então estes são reconhecidos? Enquanto os currículos são trabalhados a partir de uma visão homogênea de aluno ele continua sendo excludente. É preciso enxergar que os educandos são os sujeitos centrais no processo de ensino aprendizagem. Assim, somos desafiados diariamente em nossa prática: o que pretendemos alcançar com determinadas ações? Que tipo de formação deve ser favorecida? Como estabelecer padrões que garantam a inclusão e a formação crítica? Apple (1995) nos faz outro questionamento importante: faz sentido um currículo nacional, generalizado para todos os sujeitos tão diversos? São estas e outras que nos inquietam e nos colocam no caminho das reflexões e das buscas por mudanças.

\section{Entre o prescrito e o realizado}

Sabemos que existe uma grande distância entre o dito e o feito, entre o planejado e o praticado, como determina Vinão (2008): "uma coisa era o programa ou esquema ideal a seguir, e outra acomodá-lo às circunstâncias [...]" (p. 199). Vamos então refletir sobre os documentos que regem a 
educação básica, especificamente que tratam da EI, o que está prescrito e quais as condições peculiares de sua implementação.

De acordo com a Lei de Diretrizes e Bases da Educação Nacional (LDBEN) $\mathrm{n}^{\circ}$ 9394/96, em seu artigo 29, a finalidade da EI é "o desenvolvimento integral da criança até 5 (cinco) anos, em seus aspectos físico, psicológico, intelectual e social, complementando a ação da família e da comunidade" (BRASIL, 2017). Anteriormente a EI abrangia a faixa etária de 0 aos 6 anos de idade, a partir da Lei $n^{\circ}$ 12796/2013 houve um ano de redução. Um primeiro questionamento pode ser feito: por que abreviar a duração do ensino destinado às infâncias? $\mathrm{O}$ objetivo seria encurtar $\mathrm{o}$ processo formativo? Pretende-se assim acelerar a formação de mão de obra para o mercado de trabalho? Acreditamos que sim, apressando a formação dos cidadãos atende-se aos interesses mercadológicos, em detrimento do bem estar das crianças e do seu livre desenvolvimento. Outro fator que merece reflexão: na EI a frequência mínima exigida é de $60 \%$, enquanto para os ensinos fundamental e médio é de $75 \%$. Seria a primeira etapa da educação básica menos importante?

A Base Nacional Curricular Comum (BNCC) é um documento de caráter normativo que visa definir as aprendizagens essenciais da educação básica (educação infantil e ensino fundamental), indica conhecimentos e competências que, teoricamente, encaminham o ensino brasileiro para uma "formação humana e integral e para a construção de uma sociedade justa, democrática e inclusiva” (Brasil, 2017, p. 7). Foi aprovada em sua terceira versão, pelo CNE para se estabelecer definitivamente como um currículo nacional.

O artigo 26 da LDBEN n 9394/96, que é um dos fundamentos legais da BNCC, determina que os currículos devem ter uma base comum nacional (60\%) que será complementada, em cada sistema de ensino e em cada escola, por uma parte diversificada (40\%), ou seja, pelas características regionais e locais da sociedade, considerando suas peculiaridades culturais e econômicas. $\mathrm{Na}$ prática, as escolas optam por dois caminhos distintos: 
trabalhar a partir desta perspectiva de formação crítica e humanista de cidadão, ou, reduzir seu currículo aos conhecimentos básicos nacionais, treinando seus alunos para as avaliações. O professor Freitas (2017) alerta que tudo o que é diverso não "cai na prova", ou seja, são cobrados apenas os conteúdos obrigatórios. Assim, a parte diversificada tende a ser suprimida, prejudicando os conhecimentos regionais. Eis a importância do comprometimento emancipatório dos docentes.

O currículo tem que levar em consideração o conhecimento local e cotidiano que os alunos trazem para a escola, mas esse conhecimento nunca poderá ser uma base para o currículo. A estrutura do conhecimento local é planejada para relacionar-se com o particular e não pode fornecer a base para quaisquer princípios generalizáveis. Fornecer acesso a tais princípios é uma das principais razões pelas quais todos os países têm escolas. (YOUNG, 2007, p. 1299, grifo nosso).

Esta pode ser uma das respostas ao questionamento que Sacristan (2003) e Young (2007) nos fazem: para quê servem as escolas? O ponto de partida pode ser: a partir do conhecimento local o aluno ser capaz de ampliar e adquirir novos conceitos que se enquadram na denominada base comum. Assim, a escola não pode se limitar a treinar os estudantes para as avaliações. Favorecer o estudo dos conhecimentos regionais é um meio para construção de identidades, de censo crítico e de participantes ativos de nossa sociedade. Os docentes não podem negar esse movimento a seus educandos. Nesse processo, o conhecimento que é dinâmico, vai se construindo, se incorporando de valores próprios, a partir da mais acertada ideia de Freire (2001): não existe ensinar sem aprender. É um processo de cooperação onde não existem saberes privilegiados. No cotidiano escolar não há estabilidade, ao contrário: 
Às escolas chegam os conflitos e, como espaço social que são, elas são também cenários das relações interculturais entre grupos de diferentes classes sociais, religiões ou etnias. Nos casos de choque cultural, o multiculturalismo é um desafio a ser abordado, em caráter de urgência (SACRISTAN, 2003, p. 74).

Privilegiar o multiculturalismo representa valorizar o diverso, na tessitura de um trabalho pedagógico reflexivo construtor de identidades. De acordo com Apple (1995) existe uma falsa ideia de "cultura comum", de caráter neoconservadora ocidental. Esta, não considera a heterogeneidade de uma sociedade. O autor alerta: “entretanto, uma coisa está perfeitamente clara: o currículo nacional é um mecanismo para o controle político do conhecimento" (APPLE, 1995, p. 80). Sendo assim, não é provável que uma proposta curricular multicultural sobreviva a esse sistema controlador.

Uma simples análise pode ser feita quanto ao espaço concebido aos conhecimentos locais e regionais dentro da BNCC. Esta não foi uma conquista natural. De acordo com Gomes (2007) os movimentos sociais tiveram e continuam tendo papel fundamental, colocando "em xeque a escola uniformizadora que tanto imperou em nosso sistema de ensino" (GOMES, 2007, p. 26). A partir dos questionamentos dos currículos, tais movimentos geraram mudanças pedagógicas que interferiram nas políticas educacionais, e portanto, em suas diretrizes. Silvério (2006) também aponta que, na segunda metade do século XX, os movimentos sociais identitários foram decisivos nesse processo. Não podemos deixar este espaço que já é limitado (40\%) ser suprimido pelo majoritário. Devemos assumir uma prática docente libertadora e humanista, abraçando a lógica do diálogo, da reflexão, da empatia, entre outros (FREIRE, 1996).

É necessário entender que seguir as determinações dos documentos oficiais, de forma automática, linear e pontual, significa anular as diferenças, homogeneizar os alunos tornando-os meros receptores de uma educação excludente. É imprescindível compreender que a formação 
humana não se dá fora de um contexto político, cultural, histórico e social. Valores são construídos, identidades e diferenças também. É preciso refletir: "será que nos relacionamos com os "outros" presentes na escola, considerando-os como sujeitos sociais e de direitos?" (GOMES, 2007, p. 32, grifo do autor).

É inconcebível que a escola trate a todos da mesma forma. Os discursos em prol da igualdade muitas vezes acarretam efeito contrário, pois, ao igualar, anula as diferenças. É urgente que haja uma reorientação, um novo fazer pedagógico no sentido de oportunizar o desenvolvimento pleno dos indivíduos de acordo com suas peculiaridades.

Entram em discussão, particularmente, as muitas exclusões operadas quando os currículos estão respaldados por um entendimento de cultura universal, "maior", e, portanto, substrato dos conhecimentos que serão abordados nas diferentes instituições educativas. (COSTA; WORTMANN; BONIN, 2016, p. 527).

O movimento em prol da diversidade é histórico, e nesse sentido, a escola não pode se omitir. É preciso desconstruir a ideia de que existam grupos inferiores e grupos superiores. Devemos acreditar que toda pessoa é capaz de aprender. Como afirma Rancière (2015) "não há ignorante que não saiba uma infinidade de coisas, e é sobre este saber, sobre esta capacidade em ato que todo ensino deve se fundar" (p. 11). Dessa forma, quem se compromete com o ofício docente, deve se comprometer com a busca constante de práticas libertadoras e emancipatórias. Faz-se necessário que os currículos e, principalmente, as ações cotidianas se abram para a reflexão, analisando quais os conhecimentos são privilegiados, o que é considerado certou ou errado, o que é moral, quais são as vozes ouvidas, entre outros (SILVA, 1995).

$\mathrm{Na}$ Educação Infantil, a BNCC (2017) prevê seis direitos de aprendizagem e desenvolvimento: conviver, brincar, participar, explorar, 
expressar, conhecer-se. Determina cinco campos de experiência: o eu, o outro e o nós; corpo, gestos e movimentos; traços, sons, cores e formas; oralidade e escrita; espaços, tempos, quantidades, relações e transformações. Mas como tem sido realizado este trabalho nas escolas? Desde 2006 temos o documento Parâmetros Nacionais de Qualidade para a Educação Infantil (PNQEI) que orienta as práticas pedagógicas a partir das interações sociais: "embora dependente do adulto para sobreviver, a criança é um ser capaz de interagir num meio natural, social e cultural desde bebê" (PNQEI, 2006, p. 14). Na sequência, determina que tais interações devem ser ampliadas, em contextos coletivos de qualidade, independente de origem social, étnica, religiosa ou política.

A resolução $n^{\circ}$ 5/ 2009 fixa as Diretrizes Curriculares Nacionais para a Educação Infantil (DCNEI). Neste documento já estava estabelecida a interação social, bem como a brincadeira, como fontes de desenvolvimento, reconhecendo a criança como sujeito histórico e central no planejamento educacional.

Art. $3^{\circ} \mathrm{O}$ currículo da Educação Infantil é concebido como um conjunto de práticas que buscam articular as experiências e os saberes das crianças com os conhecimentos que fazem parte do patrimônio cultural, artístico, ambiental, científico e tecnológico, de modo a promover o desenvolvimento integral de crianças de 0 a 5 anos de idade (BRASIL, 2009).

Diante do exposto, fica clara a necessidade de liberdade, ou seja, as crianças precisam se movimentar, questionar, observar, crescer em seu coletivo e individualmente. Mas como isso é possível numa rotina onde a maior parte do tempo é destinada a atividades de leitura, cálculo, caligrafia, e principalmente, disciplinamento autoritário? Não é difícil encontrarmos em instituições de EI cadernos repletos de tarefas mecânicas e repetitivas, onde é explícita a preocupação em preparar esses alunos para o ensino 
fundamental, ou seja, acelerar o seu desenvolvimento. $\mathrm{O}$ artigo $\mathrm{n}^{\circ} 11$ do documento DCNEI (2010) determina que devem ser respeitadas as especificidades etárias, e assim, a proposta pedagógica deve favorecer a continuidade do processo de aprendizagem iniciado na primeira etapa da educação básica e continuado na segunda. Em outras palavras, não deve ser uma ruptura.

Oliveira (2017) apresenta em sua dissertação de mestrado uma pesquisa referente a escolarização precoce e a corporeidade na educação infantil. O pesquisador destaca:

A escolarização precoce, aqui, é vista como um processo pedagógico que antecipa formas de ensino e aprendizagem típicas das etapas posteriores, centralizando a ação educacional nos aspectos cognitivos em detrimento das demais dimensões do desenvolvimento, como a corpórea. A corporeidade, por sua vez, é crucial para a constituição integral dos sujeitos e está relacionada e influencia os demais fatores da formação humana (psíquico, emocional e intelectual). (OLIVEIRA, 2017, p. 8).

São muitos os casos de crianças encaminhadas ao Atendimento Educacional Especializado (AEE) por dificuldades de aprendizagem, mas que, ao serem cuidadosamente avaliadas, apresentam na verdade defasagens oriundas da EI. Sabemos que brincadeiras e interações favorecem a coordenação motora, a imaginação, o raciocínio lógico, a ampliação vocabular, dentre outros. Infelizmente, o tempo livre para a criança se desenvolver com alegria e prazer tem sido cada vez mais reduzido. Vigotsky (1991) afirma que ao brincar a zona de desenvolvimento proximal atinge o seu grau máximo. Assim, a brincadeira não pode ser uma ação aleatória ou compensatória. Deve ser uma atividade planejada, reconhecida como fonte de aprendizado e portanto legitimada pelos agentes escolares. 
De acordo com Freire (2001) se houvesse alegria e prazer em estudar certamente os índices da qualidade da nossa educação estariam melhores. Vale destacar que:

Instruir pode, portanto, significar duas coisas absolutamente opostas: confirmar uma incapacidade pelo próprio ato que pretende reduzi-la ou, inversamente, forçar uma capacidade que se ignora ou se denega a se reconhecer e a desenvolver todas as consequências desse reconhecimento. O primeiro ato se chama embrutecimento e o segundo, emancipação (RANCIÈRE, 2015, p. 11-12).

Estamos nós favorecendo este processo de emancipação? Esta é uma reflexão fundamental a todo educador comprometido com a construção de uma sociedade mais justa e democrática.

No que se refere à EI, faz-se necessário um trabalho de conscientização docente quanto ao que vem a ser esta etapa, quais as habilidades e conhecimentos devem nortear o trabalho pedagógico com as crianças. Em nenhum documento oficial está prescrito que o letramento, a alfabetização ou conhecimentos cálculos matemáticos devem ser ensinados na EI. Sabemos que a escola muitas vezes age em função da cobrança da sociedade. Assim, pais e familiares também precisam ser conscientizados afim de que não exijam da escola resultados impróprios, saberes que são próprios do ensino fundamental. Desrespeitar os tempos determinados provoca o chamado processo de escolarização precoce que, valorizando certos objetivos em detrimentos de outros, acarreta defasagens que a médio ou curto prazo poderão prejudicar o desenvolvimento global dos educandos.

\section{Considerações finais}

Trabalhar numa perspectiva emancipatória requer uma análise do que é possível fazer frente a todas as dificuldades impostas por um sistema 
centralizador. Hoje existem ações pedagógicas comprometidas com a efetivação de um sistema educacional inclusivo, assim, gradativamente este cenário tem se ampliado. Não é possível afirmar, ainda, se esta nova configuração tem se consolidado a partir de uma formação profissional voltada para a questão da inclusão, ou, se estes profissionais estão agindo meramente porque está preconizado na legislação vigente. $\mathrm{O}$ que sabemos é que existe uma abertura para o "fazer diferente", ou seja, para a construção de uma escola mais democrática. Os entraves são muitos, haja vista, por exemplo, a questão da diversidade cultural. Porém, estes desafios só vão imperar se os educadores deixarem anular seu direito de fazer um trabalho emancipatório.

Uma das direções para as quais a atenção dos pesquisadores está voltada é a que poderíamos chamar de perspectiva desconstrutiva, na qual se interroga sobre as formas como estas culturas "menores" vêm sendo representadas nos currículos, nos materiais didáticos, nos livros, nas imagens que circulam na escola, nas falas de alunos e professores, mas também em produções cinematográficas, publicitárias, televisivas, literárias, artísticas, jornalísticas, nas quais frequentemente se essencializam e se naturalizam as diferenças (COSTA; WORTMANN; BONIN, 2016, p. 528, grifo nosso).

Trabalhar nesta perspectiva "desconstrutiva" pode ser o caminho: rompendo paradigmas, favorecendo o novo, nos questionando sempre sobre "qual o papel dos elementos da dinâmica educacional e curricular envolvidos nesse processo? Qual o nosso papel, como trabalhadores culturais da educação nesse processo?" (SILVA; MOREIRA, 1995, p. 30). Sabemos que esta tarefa é complexa. Como bem esclarece Paraíso (2016):

É claro que resistir sempre implica medos e riscos. [...] A resistência possui um potencial de crescimento, florescimento e 
transformação que necessitamos para habitar a terra, para operar no campo curricular e para impedir o controle dos currículos e o silenciamento das questões de gênero e sexualidade na escola. Ela possibilita criar espaços de combates, de lutas, de insubordinação, de insurreição. A resistência é a criação de possíveis. Ela é força agenciadora que transforma e funda outras e novas relações. É esse seu potencial de criação que precisamos acionar para impedir que os desejos sejam codificados pelos poderes. (PARAÍSO, 2016, p. 408).

O professor, comprometido com o dever da emancipação, deve buscar a reflexão, a auto avaliação, a formação continuada, tendo claro seu papel, não de mestre explicador (RANCIÈRE, 2015), mas de facilitador, promotor de um ambiente propício à aprendizagem. Para Kant, citado por Streck (2012) não basta treinar as crianças, é preciso que elas aprendam a pensar.

Alves (2011) faz um questionamento que merece reflexão: "suspeito que nossas escolas ensinem com muita precisão a ciência de comprar as passagens e arrumar as malas. Mas tenho sérias dúvidas de que elas ensinem os alunos a arte de ver enquanto viajam" (p. 61). Consideramos que este "ver" representa a capacidade crítica de enxergar o implícito, a partir desta visão, elaborar questionamentos, levantar hipóteses, enfim, construir novos conhecimentos. É disso que as escolas de EI precisam, não sendo possível este trabalho numa estrutura física planejada para a homogeneização: carteiras enfileiradas, todas alinhadas, um aluno atrás do outros, todos virados para a frente da sala de aula onde o foco é o professor e o quadro negro; brincadeira somente ao final do horário, condicionada ao cumprimento de todas as tarefas e o bom comportamento durante toda a jornada. Neste cenário não há espaço para o movimento, o contato físico, a troca de experiências e o compartilhamento de materiais, as interações infantis são suprimidas por um disciplinamento autoritário que impede o desenvolvimento de saberes próprios da infância: coordenação motora, lateralidade, imaginação, criatividade, entre outros. 
De acordo com Corazza (2015) "qualquer criança tem o direito de ser criança. Mas, em todo o mundo, elas estão sendo apressadas a crescer, forçadas a amadurecer cada vez mais rápido, e a assumir responsabilidades, cada vez com menos idade (p. 257). Precisamos respeitar a infância e EI; seja em casa ou na escola, as crianças não podem ser pressionadas num processo de opressão e violência. Pais e familiares devem compreender que não é vantagem que seu filho aprenda a ler primeiro que o filho do vizinho; o proveito está no aprendizado saudável, prazeroso, fruto de interações onde a criança se torna capaz de desenvolver sua própria leitura de mundo e isso só é possível respeitando o tempo próprio da infância.

Não é nosso objetivo defender uma escola sem conteúdo, como bem afirma Streck (2012). Nossa reflexão parte do quê, ou seja, da seleção dos conhecimentos eleitos como legítimos para a escola, do como, do onde e, principalmente, para quê. Assim, deve-se "reconhecer a diversidade de situações em que eles são transmitidos e produzidos. Uma diretriz que evita transformar o ensino num "metodologismo" vazio é tomar a realidade de vida e a prática que a constitui como referência para a ação pedagógica" (STRECK, 2012, p. 20, grifo do autor). Como é vasto o campo de atuação da escola... Quantas possibilidades, quantos desafios... Não podemos, nós educadores, nos eximirmos da tarefa de reflexão quanto aos nossos objetivos educacionais, tendo claras as metas de acordo com nossa concepção de educação.

Na escola portanto o trabalho com o conhecimento não pode cingirse à apreensão de conteúdos, como significativos em si mesmos, por mais que isso possa interessar também. Os conteúdos têm de ser experimentados na sua potência transformadora como disparadores da experiência de um processo de subjetivação. Dizendo de maneira figurada, os conteúdos não são pratos feitos a serem consumidos. Têm, pelo contrário, algo de "receita", convidando os alunos à feitura do próprio alimento (LARA, 2016, p. 10, grifo do autor). 
Que nossas escolas sejam "cozinhas" de preparação do alimento saber! Comprometidos com o ensino dos conteúdos, que não podem ser desprezados, e valorizando o lúdico, vamos articulando fazeres que se somam como ingredientes de uma formação saudável e prazerosa.

Dessa forma, esperamos que a EI cumpra sua missão: muito mais que preparar os alunos para o ensino fundamental, que os saberes infantis possam ser construídos de maneira harmoniosa, favorecendo a formação de cidadão críticos e construtores de uma sociedade mais justa e democrática.

\section{Referências}

ALVES, R. Palaura para desatar nós. Campinas, SP: Papirus, 2011. 176 p.

APPLE, M. W. A política do currículo oficial: faz sentido a ideia de um currículo nacional? In: MOREIRA. A. F. B.; SILVA, T. T. da. (Org.) Currículo, cultura e sociedade. 2 ed. Revista. São Paulo: Cortez, 1995.

ARROYO, M. G. Educandos e educadores: seus direitos e o currículo. In: BEAUCHAMP, J.; PAGEL, S. D.; NASCIMENTO, A. R. do. (Org.). Indagações sobre currículo. Brasília: Ministério da Educação, Secretaria de Educação Básica, 2007. Disponível

em: $<$ http://portal.mec.gov.br/seb/arquivos/pdf/Ensfund/indag2.pdf> Acesso em 30 de novembro 2017.

BRASIL. Lei 9394 - 24 de dezembro de 1996. Lei de diretrizes e bases da educação nacional. Brasília: Senado Federal, 2017. 58 p.

. Lei 12796 - 4 de abril de 2013. Altera a Lei oㅜ 9.394, de 20 de dezembro de 1996, que estabelece as diretrizes e bases da educação nacional, para dispor sobre a formação dos profissionais da educação e dar outras providências. Disponível em: <http://www.planalto.gov.br/ccivil_03/_Ato2011-2014/2013/Lei/L12796.htm\#art1> Acesso em 30 novembro 2017.

Ministério da Educação. BASE NACIONAL COMUM CURRICULAR: educação é base. Disponível em: <http://basenacionalcomum.mec.gov.br/>. Acesso em 07 agosto 2017.

- Ministério da Educação. Parâmetros Nacionais de Qualidade para a Educação Infantil. Brasília, 2006. Disponível em: $<$ http://portal.mec.gov.br/seb/arquivos/pdf/Educinf/eduinfparqualvol1.pdf $>$ Acesso em 01 novembro 2017. 
, Ministério da Educação. Resolução CNE/ CEB $n^{\circ} 5$ de 17 de dezembro de 2009. Fixa as Diretrizes Curriculares Nacionais para a Educação Infantil. Disponível em: <http://webcache.googleusercontent.com/search?q=cache:r3FdmkVW78wJ:portal.m ec.gov.br/educacao-quilombola-/323-secretarias-112877938/orgaos-vinculados82187207/13684-resolucoes-ceb-2009+\&cd=2\&hl=pt-BR\&ct=clnk\&gl=br $>\quad$ Acesso em 02 de dezembro 2017

, Ministério da Educação, Secretaria de Educação Básica. Diretrizes curriculares nacionais para a educação infantil. Brasília: MEC, SEB, 2010. 36 p.

CHIZZOTTI, A.; PONCE, B. J.; O currículo e os sistemas de ensino no Brasil. Currículo sem Fronteiras, v. 12, n. 3, p.25-36, Set/Dez 2012 ISSN 1645-1384 (online) www.curriculosemfronteiras.org $25 . \quad$ Disponível em: <http://www.curriculosemfronteiras.org/vol12iss3articles/chizzotti-ponce.pdf.> Acesso em 07 agosto 2017

CORAZZA, S. M. Infância: desafios de todos, todos os dias. In: SANTOS, B. P.; OLIVEIRA, C. C.; MENDES, O. M. (Org.) Educação e culturas populares em diferentes contextos educativos: pesquisas e intervenções. Uberlândia: EDUFU, 2015. p. 257-272.

COSTA, M. V.; WORTMANN, M. L.; BONIN, I. T. CONTRIBUIÇÕES DOS ESTUDOS CULTURAIS ÀS PESQUISAS SOBRE CURRÍCULO - uma revisão. Currículo sem Fronteiras, v. 16, n. 3, p. 509-541, set./dez. 2016. Disponível em: $<$ http://www.curriculosemfronteiras.org/vol16iss3articles/costa-wortmannbonin.pdf $>$ Acesso em 16 setembro 2017.

FOUCAULT, M. A arqueologia do saber. $6^{\text {a }}$ ed. Rio de Janeiro: Forense Universitária, 2000. p. 201-222.

FREITAS, L. C. BNCC: primeiros impactos nos materiais didáticos. Avaliação educacional - Blog do Freitas. 14 jun. 2017. Disponível em: $<$ https://avaliacaoeducacional.com/2017/06/14/bncc-primeiros-impactos-nosmateriais-didaticos/>. Acesso em 07 agosto 2017.

FREIRE, P. Carta de Paulo Freire aos professores. Estudos avançados. Vol.15. No42. São Paulo, 2001. Disponível em: $<$ http://www.scielo.br/scielo.php?script=sci_arttext\&pid=S0103$40142001000200013>$ Acesso em 05 dezembro 2017.

- Pedagogia da autonomia: saberes necessários à prática educativa. São Paulo: Paz e Terra, 1996. 166 p.

GOMES, N. L. Diversidade e Currículo. In: BEAUCHAMP, J.; PAGEL, S. D.; NASCIMENTO, A. R. do; (Org.). Indagações sobre currículo. Brasília: Ministério da Educação, Secretaria de Educação Básica, 2007. Disponível em: $<$ http://portal.mec.gov.br/seb/arquivos/pdf/Ensfund/indag4.pdf> Acesso em 30 de novembro 2017. 
KRAMER, S. Infância, Cultura Contemporânea e Educação contra a barbárie. 2000. Disponível em: < http://www.epublicacoes.uerj.br/index.php/revistateias/article/viewFile/23857/16830> Acesso em 26 janeiro 2018.

LARA, T. A. Educação: conflitos, tarefa, desafio, perguntação, ética, subjetivação, vida, cultura, aprendizagem, alegria. Juiz de Fora: Gryphon, 2016.

MOREIRA, A. F. B.; SILVA, T. T. da. Currículo, cultura e sociedade. São Paulo: Cortez, 1994.

OLIVEIRA, T. V. Lápis na mão ou rolar no chão? Olhares sobre a escolarização precoce e a corporeidade na educação infantil. 2017. 175 f. Dissertação (Mestrado em Educação) - Universidade Nove de Julho, São Paulo. Disponível em: $<$ http://bibliotecatede.uninove.br/handle/tede/1659> Acesso em 20 de julho 2017.

PARAÍSO, M. A. A ciranda do currículo com gênero, poder e resistência. Currículo sem Fronteiras, v. 16, n. 3, p. 388-415, set./dez. 2016. Disponível em: $<$ http://www.curriculosemfronteiras.org/vol16iss3articles/paraiso.pdf> Acesso em 09 dezembro 2017.

RANCIÈRE, J. O mestre ignorante - cinco lições sobre a emancipação intelectual. Tradução Lílian do Valle. 3. ed. Belo Horizonte: Autêntica Editora, 2015. 192 p.

SACRISTAN, J. G. O significado e a função da educação na sociedade e na cultura globalizadas. In: GARCIA, R. L.; MOREIRA, A. F. (Org.). Currículo na contemporaneidade: incertezas e desafios. 4 ed. São Paulo: Cortez, 2003. p. 41-80.

SILVA, T. T. da. Currículo e identidade social: territórios contestados. In: SILVA, T. T. da (Org.). Alienígenas na sala de aula. Petrópolis: Vozes, 1995. p. 190-207.

SILVÉRIO, V. R. A diferença como realização da liberdade. In: ABRAMOWICZ, A.; BARBOSA, M. de A.; SILVÉRIO, V. R. (Org.). Educação como prática da diferença. Campinas: Armazém do Ipê, 2006, p. 5-19.

STRECK, D. Qual o conhecimento que importa? Currículo sem Fronteiras, v. 12, n. 3, p. 8-24, Set/Dez 2012. Disponível em: <http://www.curriculosemfronteiras.org/vol12iss3articles/streck.pdf $>$ Acesso em 20 agosto 2017.

VEIGA-NETO, A. De geometrias, currículo e diferenças. Educação e Sociedade, Campinas, v. 23, n. 79, p. 163-186, ago. 2002. Disponível em: $<$ http://www.scielo.br/scielo.php?script=sci_arttext\&pid=S0101-

$73302002000300009 \& \operatorname{lng}=$ pt\&nrm=iso $>$ Acesso em 11 novembro 2017.

VIGOTSKY, L. S. A formação social da mente. São Paulo: Martins Fontes, 1991.

VIÑAO, A. História das Disciplinas Escolares. Revista Brasileira de História da Educação, n. 18, p.174-216, 2008. Disponível em: 
$<$ http://rbhe.sbhe.org.br/index.php/rbhe/article/view/93/102>. Acesso em 09 setembro 2017.

YOUNG, M. Para que servem as escolas? Educação Sociedade, v.28, n.101, Campinas, $\quad 2007 . \quad$ set./dez. Disponível em: $<$ http://www.scielo.br/scielo.php?script=sci_arttext\&pid=S0101-

$73302007000400002 \& l n g=$ t\&\&rm=iso $>$ Acesso em 20 agosto 2017.

Recebido em fevereiro de 2018.

Aprovado em setembro de 2018. 